\title{
Diagnostic Value of 18F-FDG Positron Emission Tomography for Detection and Treatment Control of Malignant Germ Cell Tumors
}

\author{
Panagiotis Tsatalpas $^{a}$ Bettina Beuthien-Baumann ${ }^{b}$ Joachim Kropp ${ }^{b}$ \\ Andreas Manseck ${ }^{a}$ Claudia Tiepolt ${ }^{b}$ Oliver W. Hakenberg ${ }^{a}$ W. Burchert ${ }^{b}$ \\ Wolf G. Franke ${ }^{b}$ Manfred P. Wirth ${ }^{a}$ \\ Departments of a Urology and b Nuclear Medicine, University of Dresden, Germany
}

\author{
Key Words \\ ${ }^{18} \mathrm{~F}-\mathrm{FDG}$ positron emission tomography $\cdot$ Computed \\ tomography $\cdot$ Testis cancer $\cdot$ Treatment control
}

\begin{abstract}
Introduction: The role of positron emission tomography (PET) with 2-[ $\left.{ }^{18} \mathrm{~F}\right]$ fluoro-2-deoxy-D-glucose ([ $\left.\left.{ }^{18} \mathrm{~F}\right] \mathrm{FDG}\right)$ is currently under evaluation in urologic oncology. The aim of the present study was to investigate the use of [ $\left.{ }^{18} \mathrm{~F}\right] F D G$ positron emission tomography ([$\left.\left.{ }^{18} \mathrm{~F}\right] \mathrm{FDG}-\mathrm{PET}\right)$ in the detection and treatment control of malignant germ cell tumors compared to computed tomography (CT). Materials and Methods: Thirty-two PET studies and CT scans were carried out in 23 patients with histologically proven germ cell tumors (10 seminomas, 12 non-seminomatous germ cell tumors (NSGCT), 1 unclassified serologic recurrent disease) Lugano stage I-III. The scans were done either after initial diagnosis $(n=21)$ and/or within 3-45 days after chemotherapy was completed $(n=$ 11). PET and CT were validated either by histology $(n=7)$ or clinical follow-up of 6-11 months after the last PET study has been performed $(n=16)$. Sensitivity, specificity, accuracy, positive and negative predictive values were determined for PET and CT. Differences between
\end{abstract}

PET and CT for parameters of diagnostic value were evaluated by $\chi^{2}$ test. Results: Although not statistically significant, the sensitivity, accuracy and negative predictive value were higher for PET than for CT with respect to the detection of metastatic infradiaphragmatic and supradiaphragmatic lesions after initial diagnosis. The specificity and positive predictive value of PET and CT were comparable. After chemotherapy, PET was found to be significantly superior in specificity and accuracy compared to $\mathrm{CT}$ with respect to infradiaphragmatic lesions $(p<0.05)$. False-positive PET findings in supradiaphragmatic lesions after chemotherapy occurred in the case of inflammatory processes and resulted in a loss of specificity and accuracy compared to CT $(p<0.05)$. Conclusions: These preliminary results demonstrate [ $\left.{ }^{18} \mathrm{~F}\right] \mathrm{FDG}$ PET to be a useful diagnostic tool for the initial staging and treatment control in patients with germ cell tumors. Possible advantages compared to $\mathrm{CT}$, however, are as yet not clearly defined. The possibility of false-positive PET findings due to reactive supradiaphragmatic inflammatory processes early after chemotherapy have to be considered.

Copyright $\odot 2002$ S. Karger AG, Base

\begin{tabular}{ll}
\hline KARGER & ( 2002 S. Karger AG, Basel \\
Fax +41613061234 & \\
$\begin{array}{l}\text { E-Mail karger@karger.ch } \\
\text { www.karger.com }\end{array}$ & $\begin{array}{l}\text { Accessible online at: } \\
\text { www.karger.com/journals/uin }\end{array}$
\end{tabular}

Dr. med. Andreas Manseck

Department of Urology, University of Dresden

Fetscherstrasse 74, D-01307 Dresden (Germany)

Tel. +49 3514582162 , Fax +49 3514584333

E-Mail Andreas.Manseck@mailbox.tu-dresden.de 


\section{Introduction}

The role of positron emission tomography (PET) with 2 -[ $\left.{ }^{18} \mathrm{~F}\right]$ fluoro-2-deoxy- $D$-glucose $\left(\left[{ }^{18} \mathrm{~F}\right] \mathrm{FDG}\right)$ is currently under evaluation in urologic oncology [1-9]. Recent studies have shown that the uptake of $\left[{ }^{18} \mathrm{~F}\right] \mathrm{FDG}$ is increased in many tumor entities compared to normal tissue [10, 11]. Effective chemotherapy has been found to reduce the $\left[{ }^{18} \mathrm{~F}\right] \mathrm{FDG}$ uptake prior to volumetric changes in morphological imaging techniques such as computed tomography (CT) [12-14]. In this study, the potential of $\left[{ }^{18} \mathrm{~F}\right] \mathrm{FDG}-$ PET for the detection and treatment assessment of testicular germ cell tumors was investigated.

Malignant germ cell tumors are histologically categorized into seminomas (40\%) and into the heterogeneous group of non-seminomatous germ cell tumors $(60 \%)$ comprising embryonal carcinoma, chorionic carcinoma, malignant teratoma, yolk sac tumor and mixed or combined tumors [15].

With the introduction of cis-platinum-based polychemotherapy, the prognosis of metastatic testicular cancer has been improved dramatically and therefore germ cell tumors are today eminently curable. Cure rates of 80 90\% were reported in Lugano stage II-III patients and cure is also possible in patients who failed to achieve complete remission after initial therapy [16].

Staging after the initial diagnosis and the response of metastatic testicular cancer to chemotherapy is usually undertaken by computed tomography (CT) and by measuring the serum levels of two well-established tumor markers, $\beta$-human chorionic gonadotropin ( $\beta$-HCG) and $\alpha$-fetoprotein (AFP). However, CT-based clinical staging has been shown to have a false-negative rate in clinical stage I patients of $30-40 \%$ [17]. Also, about $40 \%$ of malignant testicular germ cell tumors cannot be monitored using the tumor markers mentioned above. After chemotherapy, almost $30 \%$ of the patients still have residual tumors on CT scanning which is unable to differentiate between vital tumor masses and residual scar tissue. Often surgery and histopathological analysis are needed to define the nature of a residual tumor mass after chemotherapy.

Due to the excellent contemporary cure rates of testicular cancer, the treatment-induced morbidity of chemotherapy and/or surgery for metastatic disease has become an important issue. Therefore, new diagnostic tools are needed to enhance the diagnostic accuracy of staging and treatment control of malignant germ cell tumors.

\section{Material and Methods}

\section{Patients}

Twenty-three patients with histopathologically proven testicular germ cell tumors were included. The histological diagnosis was seminoma in 10 patients $(43.4 \%)$, a combined tumor in $9(39.1 \%)$, embryonal carcinoma in $3(13.1 \%)$, and 1 patient $(4.4 \%)$ had an unclassified serologic recurrent disease (AFP: $631 \mathrm{ng} / \mathrm{ml}$ ) of a combined testicular tumor 2 years after initial orchiectomy. Tumor staging was assessed according to classification of the international workshop on staging and treatment of testicular cancer in Lugano [18]. The final diagnosis was stage I in $11(47.8 \%)$, stage II in $6(26.1 \%)$, and stage III in 6 patients $(26.1 \%)$. Sixteen patients received chemotherapy ( 5 of them adjuvant only) and 6 patients underwent retroperitoneal lymphadenectomy (RLA) (3 primary RLA and 3 salvage RLA). One patient received high-dose salvage PEI chemotherapy with autologous bone marrow support after initial PEB chemotherapy and 1 patient underwent mediastinal lymph node dissection with resection of a pulmonary residual tumor mass after chemotherapy. 4/7 patients with a stage I seminoma received an adjuvant radiation therapy (26 Gy), 2 an adjuvant monochemotherapy with 2 series of carboplatine and 1 patient who refused any adjuvant treatment was put on a surveillance program.

A total of 32 PET scans were carried out. The scans were done either after initial diagnosis $(\mathrm{n}=21)$ and/or within 3-45 days after chemotherapy was completed (stage II-III patients only, $\mathrm{n}=11$ ). CT scanning was done within $24 \mathrm{~h}$ of PET scanning in all patients.

\section{PET Imaging}

PET studies were performed after patients had fasted for $6-12 \mathrm{~h}$. Plasma glucose levels at the time of $\left[{ }^{18} \mathrm{~F}\right] \mathrm{FDG}$ injection were within physiological limits. Patients with diabetes mellitus were not included in the present study. $\left[{ }^{18} \mathrm{~F}\right] \mathrm{FDG}$ was provided by the Institute of Bioanorganic and Radiopharmaceutical Chemistry, Research Center Rossendorf, Germany. Patients received 185-390 MBq $\left[{ }^{18} \mathrm{~F}\right] \mathrm{FDG}$ by intravenous injection.

Fifteen of the 21 initial PET scans and all eleven PET scans after chemotherapy were carried out using an ECAT EXACT HR ${ }^{+}$PET scanner (Siemens/CTI, Knoxville, Tenn., USA). Technical data: field of view: $15.2 \mathrm{~cm} ; 63 \mathrm{~cm}$ contiguous cross-sectional slices per bed position with a slice thickness of $2.4 \mathrm{~m}$ in-plane resolution of $4-5 \mathrm{~mm}$ FWHM (full-width half-maximum). Image reconstruction was done using filtered backprojection with a $128 \times 128$ matrix size. Emission scans of the abdomen were corrected for photon attenuation by measured transmission scans using a retractable ${ }^{68} \mathrm{Ge}$ ring source. Acquisition of emission data started $60 \mathrm{~min}$ after intravenous injection of 266-390 MBq [ $\left.{ }^{18} \mathrm{~F}\right] \mathrm{FDG}$ and lasted for 50-60 min.

Six of the 21 initial $\left[{ }^{18} \mathrm{~F}\right]$ FDG scans were done using a dual head coincidence gamma camera (Solus EPIC MCD, ADAC Laboratories, Milpitas, Calif., USA). This camera covers a field of view of $38 \mathrm{~cm}$. Two to three scans overlapping 35\% were acquired in 3D mode with 32 angles of $40 \mathrm{~s}$ each. Reconstruction was performed with an iterative method implemented by the manufacturer (4 iterations, 8 ordered subsets). In-plane resolution of the device was around $4 \mathrm{~mm}$ FWHM (full-width half-maximum). Acquisition of emission data was started 60 min after intravenous injection of 100$140 \mathrm{MBq}$ and lasted for 60-90 min.

The visual analysis was graded as clearly positive when high $\left[{ }^{18} \mathrm{~F}\right] \mathrm{FDG}$ uptake was seen as a hot spot, or suspected when slightly enhanced accumulation of $\left[{ }^{18} \mathrm{~F}\right] \mathrm{FDG}$ compared with the expected

\footnotetext{
$\overline{\text { Urol Int 2002;68:157-163 }}$
}

Tsatalpas et al. 
normal distribution in the surrounding region was detected. Otherwise, the image was interpreted as negative for malignancy. The interpretation of PET scans was done by nuclear medicine specialists without knowledge of CT results.

In studies performed with the dedicated PET scanner quantitative image analysis of tumor uptake was performed by calculating the standardized uptake values (SUVs) in selected regions of interest (ROI) according to the formula [19]:

SUV =

$\underline{\text { Radioactivity concentration in } \mathrm{ROI}[\mathrm{Bq} / \mathrm{g}] \times \text { patient's weight }[\mathrm{g}]}$ injected dose $[\mathrm{Bq}]$

\section{CT Imaging}

34 CT scans (23 initial and 11 after chemotherapy) were done corresponding to all PET studies. CT scans were obtained with thirdor fourth-generation CT scanners by the Department of Radiology of the University of Dresden. Transverse cross sections of $10 \mathrm{~mm}$ slice thickness were used. Oral and intravenous contrast medium was applied for all abdominal scans. Intravenous contrast medium was given for all thoracic CT scans. CT scans for initial staging were interpreted as suspicious for metastatic lymphatic spread, if the lymph node was bigger than $1.5 \mathrm{~cm}$ and for organ metastases, if characteristic radiological signs like contrast enhancement after intravenous contrast medium application was seen. The CT images were examined by radiologists without knowledge of the PET results.

\section{Tumor Markers}

Tumor marker levels of AFP and $\beta-\mathrm{HCG}$ were available for all patients. AFP $>9 \mathrm{ng} / \mathrm{ml}$ and $\beta-\mathrm{HCG}>5 \mathrm{U} / \mathrm{l}$ were considered pathologic.

\section{Validation and Statistics}

Validation was done either by histology $(n=7)$ or by clinical follow-up of 6-11 months after the last PET study had been done $(\mathrm{n}=$ 16). Absence of disease after therapy was assumed, if patients were without signs of progression on $\mathrm{CT}$, and tumor markers were negative for at least 6 months without further treatment. Tissue for histology was obtained by retroperitoneal lymphadenectomy $(n=6)$ and thoracotomy $(\mathrm{n}=1)$.

Sensitivity, specificity, positive and negative predictive values and accuracy were determined for both PET and CT. Differences between PET and CT for these parameters of diagnostic value were evaluated by chi-square test. The accepted limit to indicate statistical significance was $p<0.05$. All statistical tests were calculated with the MEDAS statistical software package for PC (Grund, Würzburg, Germany).

\section{Results}

Accumulation of $\left[{ }^{18} \mathrm{~F}\right] \mathrm{FDG}$ was detected in 9 of 21 $(42.8 \%)$ of the primary PET studies by visual analysis. Eight were graded as clearly positive $(++)$ and one as suspect $(+)$. All lesions with primarily clearly positive visual findings represent metastatic lesions proven either by histology or clinical follow-up. The one PET study graded as suspect showed multiple retroperitoneal and mediastinal lesions with SUV values between 2.6 and 4.0. The corresponding $\mathrm{CT}$ in that case (primary histology: teratoma and embryonal carcinoma) showed multiple retroperitoneal, lung and mediastinal metastases, the largest measuring $9.2 \times 8.6 \times 15 \mathrm{~cm}$. In another case in which the CT scan suggested two metastatic lesions, a retroperitoneal and a parailiacal one, PET identified only the retroperitoneal one, but not the parailiacal lesion. The correct PET staging was proven by retroperitoneal and parailiacal lymphadenectomy, where the parailiacal lesion was verified to be an ectopic seminal vesicle. One patient showed two clearly positive retroperitoneal lesions with SUV values of 6.0 in the typical location which CT failed to identify. These lesions disappeared after 3 series of cisplatinumbased chemotherapy. In 1 patient PET scanning identified a clearly positive mediastinal metastatic lesion in contrast to CT findings, which disappeared after two series of cisplatinum-based chemotherapy. In another patient, control CT two years after orchiectomy also failed to identify metastases in spite of serologic AFP levels of $631 \mathrm{ng} / \mathrm{ml}$. In contrast to CT, PET showed one lung and multiple mediastinal lesions.

Twelve of 21 primary PET studies (57.2\%) were graded as negative in agreement with clinical and CT findings. In one of these cases (primary histology: embryonal carcinoma with seminoma) retroperitoneal lymphadenectomy identified one solitary lymph node metastasis with a histology similar to the primary tumor.

Statistical analysis of the initial findings (see also table 1 ) showed PET to be more sensitive ( 0.90 vs. 0.60$)$, accurate ( 0.95 vs. 0.81$)$ and to have a higher negative predictive value ( 0.92 vs. 0.73 ) than $\mathrm{CT}$, but these differences were not statistically significant, although the specificity and positive predictive value were in the same range as that of CT.

The PET scans after the completion of chemotherapy showed accumulation of $\left[{ }^{18} \mathrm{~F}\right] \mathrm{FDG}$ in 5 of 11 cases (45.45\%). The lesions seen in the control PET were in one of these cases in the same locations as in the primary PET and were proven to be metastases. In the other 4 cases, those lesions found to be positive in the control PET were in different locations (lung and neck) compared to the findings in the first PET scan while the primary lesions had disappeared completely. Histology after thoracotomy ( 1 of 4 cases), antibiotic treatment and clinical follow-up ( 3 of 4 cases) showed that these lesions were of an inflammatory nature.

6/11 (54.55\%) PET scans after chemotherapy showed no accumulation of $\left[{ }^{18} \mathrm{~F}\right] \mathrm{FDG}$. In 4 of these 6 patients CT 
Table 1. Primary diagnostic value of PET vs. CT $(\mathrm{n}=21)$

\begin{tabular}{llllllllll}
\hline Primary & TP & FN & TN & FP & SENS & SPEC & ACC & PPV & NPV \\
\hline W-PET & 9 of 10 & 1 of 10 & 11 of 11 & 0 of 11 & 0.90 & 1.0 & 0.95 & 1.0 & 0.92 \\
W-CT & 6 of 10 & 4 of 10 & 11 of 11 & 0 of 11 & 0.60 & 1.0 & 0.81 & 1.0 & 0.73 \\
\hline I-PET & 6 of 7 & 1 of 7 & 14 of 14 & 0 of 14 & 0.85 & 1.0 & 0.95 & 1.0 & 0.93 \\
I-CT & 5 of 7 & 2 of 7 & 14 of 14 & 0 of 14 & 0.71 & 1.0 & 0.91 & 1.0 & 0.87 \\
\hline S-PET & 4 of 5 & 1 of 5 & 16 of 16 & 0 of 16 & 0.80 & 1.0 & 0.95 & 1.0 & 0.94 \\
S-CT & 3 of 5 & 2 of 5 & 16 of 16 & 0 of 16 & 0.60 & 1.0 & 0.90 & 1.0 & 0.89 \\
\hline
\end{tabular}

$\chi^{2}$ test: $\mathrm{p} \geq 0.05$ (not significant) in all possible combinations (vertical reading).

$\mathrm{W}=$ Whole body; $\mathrm{I}=$ infradiaphragmatic; $\mathrm{S}=$ supradiaphragmatic; $\mathrm{TP}=$ true positive; $\mathrm{FN}$ = false negative; $\mathrm{TN}=$ true negative; $\mathrm{FP}=$ false positive; $\mathrm{SENS}=$ sensitivity; $\mathrm{SPEC}=$ specificity; $\mathrm{ACC}=$ accuracy; $\mathrm{PPV}=$ positive predictive value; $\mathrm{NPV}=$ negative predictive value.

Only patients with primary PET and CT scans were included in this table $(\mathrm{n}=21)$.

\begin{tabular}{llllllllll}
\hline Primary & TP & FN & TN & FP & SENS & SPEC & ACC & PPV & NPV \\
\hline W-PET & 1 of 1 & 0 of 1 & 6 of 10 & 4 of 10 & 1.0 & 0.06 & 0.64 & 0.20 & 1.0 \\
W-CT & 1 of 1 & 0 of 1 & 6 of 10 & 4 of 10 & 1.0 & 0.60 & 0.64 & 0.20 & 1.0 \\
\hline I-PET & 1 of 1 & 0 of 1 & 10 of 10 & 0 of 10 & 1.0 & $1.0^{*}$ & $1.0^{*}$ & 1.0 & 1.0 \\
I-CT & 1 of 1 & 0 of 1 & 6 of 10 & 4 of 10 & 1.0 & $0.60^{*}$ & $0.64^{*}$ & 0.20 & 1.0 \\
\hline S-PET & 1 of 1 & 0 of 1 & 6 of 10 & 4 of 10 & 1.0 & $0.60^{*}$ & $0.64^{*}$ & 0.20 & 1.0 \\
S-CT & 1 of 1 & 0 of 1 & 10 of 10 & 0 of 10 & 1.0 & $1.0^{*}$ & $1.0^{*}$ & 1.0 & 1.0 \\
\hline
\end{tabular}

$* \mathrm{p}<0.05$ (vertical reading).

$\mathrm{W}=$ Whole body; $\mathrm{I}=$ infradiaphragmatic; $\mathrm{S}=$ supradiaphragmatic; $\mathrm{TP}=$ true positive; $\mathrm{FN}$ = false negative; $\mathrm{TN}=$ true negative; $\mathrm{FP}=$ false positive; $\mathrm{SENS}=$ sensitivity; $\mathrm{SPEC}=$ specificity; $\mathrm{ACC}=$ accuracy; $\mathrm{PPV}=$ positive predictive value; $\mathrm{NPV}=$ negative predictive value.

identified residual tumor masses. After retroperitoneal lymphadenectomy in three cases, these masses were shown by histology to be scar tissue and an ectopic seminal vesicle without vital tumor cells. One case with a residual retroperitoneal tumor mass $(2.8 \times 1.0 \mathrm{~cm}$ in $\mathrm{CT}$; primary histology: seminoma) is still without progression after 8 months. The other 2 patients with negative PET scans after chemotherapy showed also a complete remission with respect to control CT and serologic tumor markers. They are still in remission after a follow-up period of 8 to 11 months.

The statistical analysis of the findings after chemotherapy (table 2) showed no significant differences between PET and CT values with respect to whole body detection. When PET was compared to CT with respect to infra- diaphragmatic lesions only, PET was shown to be superior in specificity ( 1.0 vs. 0.60$)$, accuracy ( 1.0 vs. 0.64$)$ and positive predictive value (1.0 vs. 0.20 ). However, significant differences between PET and CT were achieved only for specificity and accuracy $(\mathrm{p}<0.05)$, but not for the positive predictive value, although sensitivity and negative predictive value were in the same range as that of CT. Only in the case of supradiaphragmatic lesions was CT shown to be more specific ( 1.0 vs. 0.60 ), accurate (1.0 vs. 0.64 ) and to have higher positive predictive value (1.0 vs. $0.20)$ compared to PET. Statistical significance was seen only for the specificity $(\mathrm{p}<0.05)$ and accuracy $(\mathrm{p}<0.05)$, but not for the positive predictive value. Sensitivity and negative predictive value were in the same range as PET. 


\section{Discussion}

Due to excellent cure rates in testicular cancer, the morbidity induced by chemotherapy [22-24] and surgery has become an important issue. Therefore, new diagnostic methods are needed to enhance the diagnostic value for staging and treatment control of malignant germ cell tumors.

There are only few reports about PET using $\left[{ }^{18} \mathrm{~F}\right] \mathrm{FDG}$ in the evaluation of germ cell cancer published so far $[1,3$, 4, 6-9]. This is due to the low availability of PET scanners and the high costs of the PET examination, that is about 1.5 times of a thoracic and abdominal CT examination. In the present study, primary PET seemed to be more sensitive, accurate and to have a higher negative predictive value compared to CT. However, this was not statistically significant, a result comparable to the findings of Cremerius et al. [9]. In this relatively small group, positron imaging was able to identify metastases in 3 patients in whom CT showed no evidence of metastatic disease. MuellerMattheis et al. [7] could identify 2 patients with retroperitoneal metastases by PET imaging in a group of 7 patients with clinical (CT) stage I non-seminomatous germ cell tumors; however, there was no statistical evaluation in comparing PET and CT in their study. In contrast to those findings, Cremerius et al. [6,9] could not demonstrate any significant differences between $\mathrm{CT}$ and primary metastatic PET scans in a group of 12 and 13 patients, respectively.

Statistical analysis of our findings after chemotherapy showed no significant differences between PET and CT values with respect to whole body detection. Similar data were reported by Cremerius et al. [6] in a group of 13 patients who received their PET scans within the first two weeks after the completion of chemotherapy and by Mueller-Mattheis et al. [7] in a group of 8 patients. In contrast to those and to our own findings, Cremerius et al. [6] were able to show significant differences between PET and CT in specificity and accuracy, if PET was performed more than 13 days after chemotherapy $(n=29)$. Stephens et al. [3] considered PET to be useful for detection of residual viable testicular carcinoma following chemotherapy, without, however, no statistical evaluation in their study. Nuutinen et al. [4] found that $\left[{ }^{18}\right.$ F]FDG imaging of metastatic testicular cancer after chemotherapy has limited value because of a potentially high accumulation of $\left[{ }^{18} \mathrm{~F}\right] \mathrm{FDG}$ in inflammatory tissues. Similar data were reported by Strauss [25] for other tumor entities. None of the authors mentioned above $[4,6,7,25]$ distinguish between supradiaphragmatic and infradiaphragmatic le- sions or compare statistical parameters of diagnostic value such as specificity, accuracy, etc., for positron imaging analysis with $\left[{ }^{18} \mathrm{~F}\right] \mathrm{FDG}$ versus $\mathrm{CT}$ scanning.

The fact that all four false-positive findings in PET after chemotherapy in the present study concerned supradiaphragmatic locations, undetectable by CT and of inflammatory origin, encouraged us to examine differences between PET and CT for parameters of diagnostic value for infra- and supradiaphragmatic lesions separately. When PET was compared to CT with respect to infradiaphragmatic lesions only, PET was shown to be superior in specificity, accuracy and positive predictive value. However, statistical significance was achieved only for specificity and accuracy $(\mathrm{p}<0.05)$ but not for positive predictive value. Sensitivity and negative predictive value were in the same range as CT. For supradiaphragmatic lesions, CT was shown to be more specific, accurate and to have a higher positive predictive value in comparison to PET. Only values for specificity $(\mathrm{p}<0.05)$ and accuracy $(p<0.05)$ were statistically significant but not those for the positive predictive value, although sensitivity and negative predictive value were in the same range as PET.

These results after chemotherapy demonstrate $\left[{ }^{18} \mathrm{~F}\right] \mathrm{FDG}$ positron imaging to be useful as a diagnostic tool for the treatment control with respect to infradiaphragmatic lesions. On the other hand, CT seems to be superior compared to PET in treatment control with respect to supradiaphragmatic lesions. One possible explanation of these findings is that all false-positive lesions were supradiaphragmatic in patients in whom the PET scans were done within the first 10 days after the completion of chemotherapy. In this time interval after chemotherapy it can be assumed that patients are in a state of relative immunodeficiency which might promote infections especially in regions exposed to an environmental flora as that of the oropharynx and the respiratory tract. The infradiaphragmatic space and especially the retroperitoneal space, excluding the gastrointestinal tract, are not primarily in contact with a bacterial flora so that there is probably a lower probability for infections in these regions which might result in inflammation and thus in false-positive PET findings.

This hypothesis might serve as a possible explanation why $\left[{ }^{18} \mathrm{~F}\right] \mathrm{FDG}-\mathrm{PET}$ was found to be superior to $\mathrm{CT}$ in specificity and accuracy with respect to infradiaphragmatic lesions. Considering that the accumulation of $\left[{ }^{18} \mathrm{~F}\right] \mathrm{FDG}$ can be enhanced by radiation therapy up to several months following treatment [25], we must emphasize that the present results only concern patients treated by chemotherapy. It is also reported in the literature [25, 
26] that acute pancreatitis and hepatitis as well as any other inflammatory diseases with lymphocyte and macrophage accumulation may lead to false-positive results in PET studies.

Due to our findings and those of others $[4,6,25,26]$, we suggest that a complete physical examination is required before a PET scan is done in order to avoid falsepositive findings after chemotherapy. Also blood tests including C-reactive protein as well as liver and pancreas enzymes should be done at the day of PET examination. In patients with pancytopenia in whom a low $\left[{ }^{18} \mathrm{~F}\right] \mathrm{FDG}$ activity in tumor cells can be expected [6], and a relative immunodeficiency exists which promotes infections, PET studies are likely to yield false-positive results. If there are any clinical or serological signs of inflammatory disease, the PET scan should be postponed. The physician evaluating PET scans should be aware of such clinical and serologic findings. Cremerius et al. [6] suggested that the PET scans should be done not earlier than 2 weeks after the completion of chemotherapy, in order to avoid the falsepositive findings. We suggest to wait for a time interval of at least 10 days after chemotherapy. However, further investigations are necessary to define the exact time interval.

\section{Conclusions}

These preliminary results demonstrate $\left[{ }^{18} \mathrm{~F}\right] \mathrm{FDG}$ positron imaging to be a useful diagnostic tool for the initial staging and treatment control in patients with germ cell tumors. Possible advantages compared to $\mathrm{CT}$ are not yet clearly defined. Especially in patients with a positive marker and a negative CT scan, PET may be able to identify the metastatic lesion. However, supradiaphragmatic inflammatory processes after chemotherapy resulting in false-positive PET findings are a disadvantage of this method. In order to avoid false-positive findings, a close cooperation between the physicians and those who interpret the PET scan are important. Further investigations are needed to define the time interval after chemotherapy, which is necessary for nonspecific inflammatory changes to subside sufficiently until PET can be expected to have a reasonable diagnostic accuracy and specificity again.

\section{Acknowledgements}

We thank Professor Dr. B. Maurer-Schultze für her valuable suggestions in the preparation of the manuscript.

\section{References}

1 Wilson CB, Young HE, Ott RJ, Flower MA, Cronin BF, Pratt BE, McCready VR, Horwich A: Imaging metastatic testicular germ cell tumors with 18 FDG positron emission tomography, prospects for detection and management. Eur J Nucl Med 1995;22:508-513.

2 Bachor R, Kocher F, Gropengiesser F, Reske SH, Hautmann RE: Positronenemissionstomographie: Einführung eines neuen Verfahrens in die Diagnostik urologischer Tumoren. Urologe [A] 1995;34:138-142.

3 Stephens AW, Gonin R, Hutchins GD, Einhorn LH: Positron emission topography evaluation of residual radiographic abnormalities in postchemotherapy germ cell tumor patients. J Clin Oncol 1996;14:1637-1641.

4 Nuutinen JM, Leskinen S, Eloma I, Minn H, Varpula M, Solin O, Söderström KO, Joensuu $\mathrm{H}$, Salminen E: Detection of residual tumors in postchemotherapy testicular cancer by FDGPET. Eur J Cancer 1997;33:1234-1241.

5 Kosuda S, Kison P, Greenough R, Grossman B, Wahl RL: Preliminary assessment of fluorine-18 fluorodeoxyglucose positron emission topography in patients with bladder cancer. Eur J Nucl Med 1997;24:615-620.
6 Cremerius U, Effert PJ, Adam G, Sabri O, Zimny M, Wagenknecht G, Jakse G, Buell U: FDG PET for detection and therapy control of metastatic germ cell tumor. J Nucl Med 1998; 39:815-822.

7 Müller-Mattheis V, Reinhardt M, Gerharz CD, Fürst G, Vosberg H, Müller-Gärtner HW, Ackermann R: Die Positronenemissionstomographie mit $\left[{ }^{18} \mathrm{~F}\right]$-2-fluro-2-deoxy- $D$-glukose (18FDG-PET) bei der Diagnostik retroperitonealer Lymphknotenmetastasen von Hodentumoren. Urologe [A] 1998;37:609-620.

8 Albers P, Bender H, Yilmaz H, Schoeneich G, Biersack HJ, Mueller SC: Positron emission topography in the clinical staging of patients with stage I and II testicular germ cell tumors. Urology 1999;53:808-811.

9 Cremerius U, Wildberger JE, Borchers H, Zimny M, Jakse G, Guenther RW, Buell U: Does positron emission tomography using 18Fluoro-2-deoxyglucose improve clinical staging of testicular cancer? Results of a study in 50 patients. Urology 1999;54:900-904.

10 Strauss LG, Conti PS: The applications of PET in clinical oncology. J Nucl Med 1991;32:623648.
11 Goldberg MA, Lee MJ, Fischmann AJ: Fluorodeoxyglucose PET of abdominal and pelvic neoplasms, potential role in oncologic imaging. Radiographics 1993;13:1047-1062.

12 Hoekstra O, Ossenkoppele G, Golding R: Early treatment response in malignant lymphoma, as determined by planar fluorine-1,8-fluorodeoxyglucose scintigraphy. J Nucl Med 1993;34: 1706-1710.

13 Wahl RL, Zasadny K, Helvie M: Metabolic monitoring of breast cancer chemotherapy using positron emission tomography: Initial evaluation. J Clin Oncol 1993;11:2101-2111.

14 Haberkorn U, Strauss LG, Dimitrakopoulou A, Seifert E, Obersdorfer F, Ziegler S, Reisser C, Doll J, Helus F, van Kaick G: Fluorodeoxyglucose imaging of advanced head and neck cancer after chemotherapy. J Nucl Med 1993; 34:12-17.

15 Horwich A: Testicular germ cell tumors, an inductory overview; in Horwich A (ed): Investigation and Management of Testicular Cancer, ed 1. London, Chapman Hall Medical, 1991, pp 1-13.

16 Garnick NB: Testicular cancer and other trophoblastic diseases; in Isselbacher KJ, Braunwald E, Wilson JD, et al (eds): Harrison's Principles of Internal Medicine, ed 13. New York, McGraw-Hill, 1994, pp 1858-1862. 
17 Fernandez EB, Moul JW, Foley JP, Colon E, McLeod DG: Retroperitoneal imaging with third and fourth generation computed axial tomography in clinicals stage I nonseminomatous germ cell tumors. Urology 1994;44:548552.

18 Cavalli F, Monfardini S, Pizzocaro G: Report on the international workshop on staging and treatment of testicular cancer. Eur J Cancer 1980;16:99-101.

19 Woodward HQ, Gigler RE, Freed B, Russ G: Expression of tissue isotope distribution. J Nucl Med 1975;16:958-959.
20 Bajorin DF, Herr H, Motzpr RJ, Bosl GJ: Current perspectives on the role of adjunctive surgery in combined modality: Treatment for patients with germ cell tumors. Semin Oncol 1992;19:148-158.

21 Baniel J, Foster RS, Rowland RG, Bihrle R, Donohue JP: Complications of postchemotherapy retroperitoneal lymph node dissection. J Urol 1995;153:976-980.

22 Bokemeyer C, Berger CC, Kuczyk MA, Schmoll HJ: Evaluation of long-term toxicity after chemotherapy for testicular cancer. J Clin Oncol 1996;14:2923-2932.

23 Jakob A, Kollmannsberger C, Kanz L, Bokemeyer C: Spättoxizität nach Chemotherapie maligner Hodentumoren. Urologe [A] 1998;37: 635-647.
24 Fossa SD, Aass N, Ous S, Waehre H: Longterm morbidity and quality of life in testicular cancer patients. Scand J Urol Nephrol 1991; 138(suppl):241-246.

25 Strauss LG: Fluorine-18 deoxyglucose and false-positive results, a major problem in the diagnostics of oncological patients. Eur J Nucl Med 1996;23:1409-1415.

26 Kubota R, Yamada S, Kubota K, Ishiwata K, Tamahashi N, Ido T: Intratumoral distribution of fluorine-18-fluorodeoxyglucose in vivo, high accumulation in macrophages and granulation tissues studied by microautoradiography. J Nucl Med 1992;33:1972-1980. 